NASA Technical Memorandum 106027

\title{
Multidisciplinary Tailoring of Hot Compoșite Structures
}

Surendra N. Singhal

Sverdrup Technology, Inc.

Lewis Research Center Group

Brook Park, Ohio

and

Christos C. Chamis

National Aeronautics and Space Administration

Lewis Research Center

Cleveland, Ohio

Prepared for the

33rd Structures, Structüral Dynamics and Materials Conference cosponsored by the AIAA, ASME, ASCE, AHS, and ASC

Dallas, Texas, April 13-15, 1993 


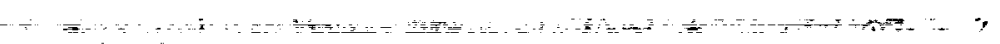

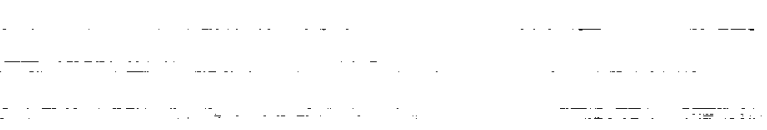

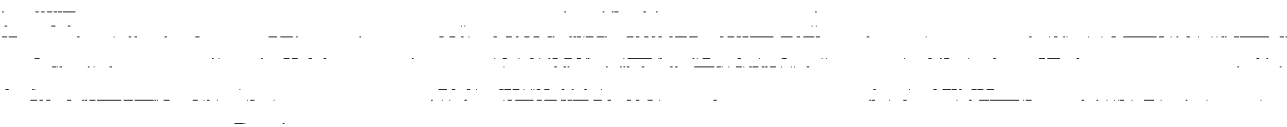




\author{
Surendra N. Singhal ${ }^{1}$ \\ Sverdrup Technology, Inc. \\ Lewis Research Center Group \\ Brook Park, Ohio 44142 \\ Christos C. Chamis ${ }^{2}$ \\ National Aeronautics and Space Administration \\ Lewis Research Center \\ Cleveland, Ohio 44135
}

\title{
Abstract
}

A computational simulation procedure is described for multidisciplinary analysis and tailoring of layered multi-material hot composite engine structural components subjected to simultaneous multiple discipline-specific thermal, structural, vibration, and acoustic loads. The effect of aggressive environments is also simulated. The simulation is based on a three dimensional finite element analysis technique in conjunction with structural mechanics codes, thermal/acoustic analysis methods, and tailoring procedures. The integrated multidisciplinary simulation procedure is general-purpose including the coupled effects of nonlinearities in structure geometry, material, loading, and environmental complexities. The composite material behavior is assessed at all composite scales, i.e., laminate/ply/constituents (fiber/matrix), via a nonlinear material characterization hygro-thermo-mechanical model. Sample tailoring cases exhibiting nonlinear material/loading/environmental behavior of aircraft engine fan blades, are presented. The various multidisciplinary loads lead to different tailored designs, even those competing with each other, as in the case of minimum material cost versus minimum structure weight and in the case of minimum vibration frequency versus minimum acoustic noise.

\section{Introduction}

Advanced composite materials are making inroads in structural applications in general, and in propulsion systems in particular, leading to light weight, structurally sound and cost effective replacements of conventional materials. In cases such as the High Speed Civil Transport with extreme cemperatures, conventional materials simply won' $\tau$ suffice. The feasibility of an acceptable design hinges on the use of advanced composite materials which can be tailored for required performance. Designing with composite materials poses multi-faceted challenges in the areas of material selection, fabrication processes, thermostructural interaction, durability, and life. Then, there are special considerations such as acoustic noise. The design process is further compounded due to additional complexities such as aggressive environments, nonlinear material/structural behavior, and coupling between responses induced by discipline-specific loads. Present design procedures are usually based on loosely coupled tailoring schemes. The result is a design which satisfies some, but not all, sometimes conflicting requirements, resulting in premature failures. Clearly, coupled multidisciplinary analysis/tailoring methods capable of simulating all involved discipline-specific loads and their interaction with each other, are needed. Experiments being generally expensive and requiring a relatively long time from developing the test methods to interpreting the results, computational simulation of the physical phenomena governing the response of the structure, is the cost-effective way of designing complex composite structures. 
One of the early efforts recognizing the need for developing coupled multidisciplinary analysis and tailoring methods/codes, is described in a National Aeronautics and Space Administration (NASA) report ${ }^{2}$. The effort continues to evolve and contains a multitude of discipline-specific as well as integrated codes covering a vast spectrum of consistent, compatible, and interactive methods/computer codes ${ }^{2}$. Recently, a stand-alone multidisciplinary analysis and tailoring procedure/code was developed by integrating the three dimensional finite element analysis method with several single-discipline (thermal, acoustic ${ }^{3}$ ) codes including those for integrated composite mechanics ${ }^{4}$ and optimization methods ${ }^{5}$.

The objective of the present paper is to demonstrate the computational simulation of the multidisciplinary design tailoring procedures for layered multi-material hot composite structures, exemplified for propulsion components (Fig. 1).

\section{Multidisciplinary Tailoring - Brief Description}

A general-purpose methodology based on finite elements formulation was developed to computationally simulate the coupled multidisciplinary heat transfer, siructural, vibration, and acoustic tailoring of hot composite structures in propulsion environments. The various disciplines are coupled for nonlinear geometrical, material, and environmental effects. Fig. 2 shows the integrated multidisciplinary analysis and tailoring methodology for computationally simulating the response of composite structures. The various single-discipline analysis capabilities are listed on the top center of Fig. 2 . The thermal, mechanical, and acoustic properties of the composite material are nonlinear functions of parameters such as temperature and environments. The composite mechanics, used for computing laminate properties for structural analysis and for computing the local structural response at various composite scales, is handled via an Integrated Composite Analyzer, ICAN". An optimizer based on feasible directions formulation is used for tailoring the results of the multidiscipinary analysis.

The Integrated Composite Analyzer ICAN, shown in Fig. 3, is used for determining thermal/mechanical properties at various scales (fiber/matrix constituents. ply, and laminate) of the composite structure based on composite micro-mechanics and laminate theories, given the reference properties of the constituents. A nonlinear material characterization hygro-thermo-mechanical mode $l^{6}$ shown in Fig. 4, is used at the matrix scale to simulate the degradation in material properties due to applied temperature, time, and environmental effects, via an iterative approach, as shown in Fig. 3. The ICAN module uses composite micromechanics and laminate theories to automatically calculate the multi-scale composite properties of the undamaged arbitrary combinations of layered multi-material composite configurations, as well as for the degraded configurations at various stages of the composite structure life-cycle. The room temperature properties of fiber/matrix constituents for typical aircraft structure materials are automatically extracted from the ICAN resident data bank which can be augmented for properties of new materials. This feature results in a considerable saving of tie required for searching and inputting the composite material property data.

The modular structure of the computer code developed based on the methodology described above, is shown in Fig. 5. The simulation procedure is controlled through an executive module. The user provides the input through the executive module as shown on top center of Fig. 5. The left side of Fig. 5 shows the analysis mociles as requir $d$ by the various discipline-specific loads. As shown on the right side of Fig. $\equiv$. the code contains a dedicated database for efficient 
data manipulation, noninear solvers and history tracking routines to simulate the various nonlinearities and time dependencies, and several utility routines for resident data processing capabilities. The output, as shown on the bottom center of Fig. 5, can be in various forms including tables, graphs, and videos.

The tailoring procedure is shown in Fig. 6. The first step is the specification of the tailoring input. The tailoring input consists of the objective function, design variables, constraints, and convergence tolerances. The next step is to establish the current design via the initial multidisciplinary analysis based on values of the current design variables. The many discipline-specific loads activate the required multidisciplinary analysis modules, listed on the right side of Fig. 6 . It can be seen in Fig. 6 that the cailoring procedure is iterative. The gradients of the objective function and constraints are computed with respect to the design variables. The search direction vector is defined. A new set of design variables is chosen along the search direction. A new proposed design based on the new design variables is then simulated. The multidisciplinary analysis is used for computing the new design. Based on the specified tolerances, the objective function, design variables, and constraints are checked for an optimum design. The iterative procedure is repeated until an optimum design, that satisfies all the constraints, is reached.

Fig. 7 shows the flow of the various multidisciplinary analysis modules needed for multidisciplinary tailoring. First, the Model Definition module generates the finite element model of the structure geometry, composite configuration, boundary conditions, and loads. The Integrated Composite Analyzer module, ICAN ${ }^{4}$ is then used for determining the thermal and mechanical properties at various scales (fiber/matrix constituents, ply, and laminate) of the composite structure, as explained in Fig. 3.

The computational procedure for coupled heat transfer, structural, vibration, and acoustic analysis is based on the three dimensional finite element formulation. The heat transfer response is computed via the Thermal Analysis module, THEAN, capable of performing linear steady state, nonlinear steady state, linear transient, and nonlinear transient analyses with thermal properties computed and updated via the ICAN module. The coupled composite-mechanics/heattransfer analyses with iteratively tailored design updates, thus, allow thermal cailoring of composite materials/structures.

The same finite element mesh that was used for the heat transfer analysis, is also used for the structural and vibration analyses. This minimizes the data preparation time and eliminates the errors incurred in transforming the cemperatures from one finite element mesh to another. Two types of structural analyses: (1) static and (2) buckling can be performed, at the end of any heat transfer analysis step. The vibration analysis computes the modal response, ie., the free vibration frequencies and mode shapes. The environmental effect (temperature and moisture) on the structural and vibration response is accounted for via the ICAN module. Nonlinear geometric effects such as large deformation/centrifugal stiffening are accounted for via updated Lagrange analysis. The local structural response at ply and fiber/matrix scales of the composite structure, is computed via ICAN, as shown on the right side of Fig. 3. The structural and vibration tailoring of composite structures can be performed including the coupling hetween all interactive disciplines (compositemechanics/heat-transfer/structural-analysis/vibrations) including geometric, material, and loading nonlinearities and environmental effects.

The acoustic analysis module, ACOAN computes the acoustic noise emitted from the composite structure, due to (1) free vibration, or (2) forced vibration 
induced by applying a force at a point of the structure, selectively exciting the vibration modes of interest. The acoustic noise is computed by first calculating radiation efficiencies of the structure for each natural vibration mode as a function of forced vibration frequency. The total noise power for each forced vibration frequency is then calculated by summing the contribution from each free vibration mode. A part of the structure can be masked from emitting the noise. The acoustic tailoring of composite structures can be performed with desired coupling between all interacting disciplines (composite-mechanics/heattransfer/structural-analysis/vibration/ acoustic-noise) including geometric, material, and loading nonlinearities and environmental effects.

The multi-load step analysis feature allows coupling among all the participating disciplines by passing the updated geometry and updated material behavior back to any one or all analysis disciplines via a nonlinear iterative procedure.

The coupling between the various disciplines due to geometrical, material, loading, and environmental complexities described above, allows many combinations of coupled multidisciplinary analyses, as has been demonstrated for a fan blade ${ }^{7}$. There are several other advanced features in this computational simulation procedure, not discussed herein as they are not included in the demonstration cases presented in this paper.

\section{Sample Cases - Fan Blade}

A layered, multi-material aircraft engine fan blade was tailored for multidisciplinary thermal, vibration, and acoustic response as well as material cost and structure weight. The geometry, boundary conditions, material, composite configuration, environment, and thermal/structural/acoustic loads are shown in Fig. 8. A summary of the various tailoring cases including the objective function, design variables, and constraints, is provided in Table 1.

\section{Blade Structure, Material, and the Finite Element Model}

The blade consists of a twisted aerofoil shape with varying thickness along the span. As shown in Fig. 8, the blade is made of layered multi-material composite - $50 \%$ thickness of titanium core and $50 \%$ thickness of outer layers of T300/IMHS material with 30 degree Iiber orientation (with respect to the radial direction, $x$ ) and 0.6 fiber volume ratio. The T300 stands for the graphite fibers and IMHS for intermediate high strength epoxy matrix. The thermal and mechanical properties of the $T 300$ fibers and IMHS matrix at room temperature can be found in Ref. 7. The finite element model consisted of 4020 -noded ( 8 corner and 12 mid-side) brick elements with 110 rodes.

\section{Thermal Tailoring}

The root of the blade was held at a constant temperature of $200^{\circ} \mathrm{F}$ and the blade surface was subjected to fluid flow at $300^{\circ} \mathrm{F}$ (Fig. 8). The thermal material properties; thermal conductivity and coefficient of heat convection, were considered temperature-dependent via the Integrated Composite Analyzer, ICAN. A nonlinear steady-state heat transfer analysis coupled with composite mechanics was conducted. Two tailoring cases were performed: (1) for minimizing the maximus blade temperature, and (2) for minimizing the maximum blade temperature gradient. The design variables include thickness and orientation of the layers, with different upper and lower bounds for different material layers, as shown in Table 1 . The total blade thickness is constrained to remain constant.

The thermal tailoring of the far. jlade resulted in about $5 \%$ reduction of the maximum temperature and about $17 \%$ reduction of the maximum temperature gradient, 
which will significantly reduce thermal stresses in the tailored design. The design before and after tailoring, for the minimization of maximum temperature gradient, is shown in Fig. 9. The tailoring paths for the objective function and design variables are shown in Fig. 10. The thickness of the less thermally conductive titanium layer decreased up to its specified lower bound and the combined thickness of the T300/IMHS layers increased so as to keep the total blade thickness constant. Similarly, the orientation of the T300/IMHS layers became more radial (than circumferential) to maximize thermal conduction in the radial direction, consistent with higher thermal conductivity of the fibers compared to that of the matrix.

\section{Vibration Tailoring}

The root of the blade was fixed. Two tailoring cases were performed at room temperature with no moisture absorption: (1) for minimizing the fundamental vibration frequency, and (2) for maximizing the fundamental vibration frequency. The design variables include orientation of all layers with upper and lower bounds, as shown in Table 1 . The total blade thickness is constrained to remain constant. The second and third vibration frequencies are also constrained by upper and lower bounds.

The vibration tailoring of the fan blade resulted in about $18 \%$ reduction for the minimization of the fundamental vibration frequency. And, the maximization of the fundamental vibration frequency resulted in about $64 \%$ increase. The tailoring results for the maximization of fundamental vibration frequency are shown in Figs. 11 and 12 . The orientation of the T300/IMHS layers became more radial (than circumferential) to maximize the stiffness in the radial direction, consistent with higher stiffness of the fibers compared to that of the matrix.

\section{Acoustic Tailoring}

The root of the blade was fixed and sinusoidal forced vibrations of $10 \mathrm{lb}$ amplitude were applied at the leading edge tip in the blade thickness direction, at the forcing frequency of $79 \mathrm{cps}$ (Fig. 8). Note that the fundamental vibration frequency of the blade is $79.1 \mathrm{cps}$. One tailoring case was performed for minimizing the acoustic noise emitted from the fan blade at room temperature with no moisture absorption. The design variables include orientation of the layers, with upper and lower bounds, as shown in Table 1. The total blade thickness is constrained to remain constant. It is to be noted that the tailoring can be performed with many special features available in the simulation procedure, but not demonstrated in the present paper. One such feature is the inclusion of the damping of the composite material and its interaction with material and environmental parameters. The modal loss factors used for this evaluation are only estimates. The computational simulation of damping in composite materials has been developed ${ }^{8,9}$ and will be included in future studies.

The tailoring for acoustic noise emitted from the fan blade resulted in about $85 \%$ reduction in noise power. The equivalent reduction in decibels is about $9 \%$ which is significant considering the fact that the decibel scale is logarithmic. The tailoring results for the minimization of acoustic noise are shown in Figs. 13 and 14. To minimize the acoustic noise from the fan blade, its composite configuration must change to cause maximum difference between the applied forced acoustic excitation frequency and the changed blade vibration frequency. Since, the 79.1 cps vibration frequency of the fan blade is very close to the 79 cps forced acoustic excitation frequency, the noise level can be decreased by either decreasing or increasing the blade vibration frequency. However, as noced in the vibration tailoring results, the maximum tailorable reduction in the blade vibration frequency was only about 18\%, whereas the maximum tailorable increase in it was a significant $64 \%$. تience, the minimum noise level is achieved by increasing the blade vibration frequency which occurs by aligning the T300/IMHS 
fibers more towards the radial direction. Note that above discussion is based on the fundamental vibration mode. The total noise level emitted from the blade depends on the modal summation of the noise power generated due to all blade vibration modes. However, for the sample case under discussion, the major contribution to the noise power is from the fundamental vibration made.

\section{Cost Tailoring}

The material cost for the $T 300$ fibers was considered to be five times that of titanium. One tailoring case was performed for minimizing the material cost for the composite fan blade. The design variables include thickness of all layers, with different upper and lower bounds for different materials, as shown in Table 1. The total blade thickness is constrained to remain constant.

The material cost tailoring of the fan blade resulted in about $27 \%$ reduction in the total material cost. The tailoring results are shown in Fig. 15. The tailored design shows a significant reduction in the more expensive T300/IMHS layer thicknesses versus an increase in the less expensive titanium layer thickness, up to its allowable upper bound.

\section{Weight Tailoring}

The density for titanium is about three times that of T300/IMHS composite. One tailoring case was performed for minimizing the structure weight for the composite fan blade. The design variables include thickness of all layers, with different upper and lower bounds for different materials, as shown in Table 1 . The total blade thickness is constrained to remain constant.

The structure weight tailoring of the fan blade resulted in about $30 \%$ reduction in the total structure weight. The tailoring results are shown in Fig. 16. The tailored design shows a significant combined increase in lighter weight T300/IMHS layer thickness versus a reduction in the heavier weight titanium layer thickness, up to its allowable lower bound.

\section{Tailoring in Aggressive Environments}

Sample cases were simulated for multidisciplinary tailoring in aggressive environments. The effect of propulsion environments was simulated for tailoring the vibration and acoustic response under (1) uniform temperature rise from 70 to 300 of with no moisture absorption and (2) combined uniform temperature rise from 70 to $300^{\circ} \mathrm{F}$ and $2 \%$ absorption of moisture in the composite, by weight. The thermal and mechanical properties were considered temperature-dependent via ICAN.

The current and tailored fundamental vibration frequency and acoustic noise emitted from the blade for the various environmental conditions are shown in Figs. 17 and 18, respectively. As the temperature and moisture absorption increase: (1) the vibration frequency, both for the current and tailored designs, decreases due to degradation in the material stiffness, and (2) the acoustic noise emitted from the blade undergoes competing influences. The forced acoustic excitation frequency moves farther away from the blade vibration frequency causing decreased noise levels and the blade material becomes less stiff causing increased vibration amplitudes and hence increased noise levels. Fig. 18 shows an increase in the noise level due to increased temperature and moisture absorption.

In summary, minimization of maximum blade temperature/maximum temperature gradient, maximization of vibration frequency, and minimization of acoustic noise require T300 fibers to be oriented more in the radial (than circumferential) irection. However, zailored fiber orientations differ significantly for different tailoring disciplines. And, minimization of maximum blade 
temperature/maximum temperature gradient/structure weight require thicker T300/IMHS layers whereas minimization of cost requires thicker titanium layers.

The significant observation is that the various multidisciplinary loads lead to different tailored designs, sometimes just opposite of each other, as in the case of (1) minimum material cost versus minimum structure weight, (2) minimum vibration frequency versus minimum acoustic noise, and (3) minimum vibration frequency versus minimum temperature/temperature gradient. The multidisciplinary analysis/tailoring procedure/code demonstrated in the present paper provides a complete set of results for all applicable loads via one single code, minimizing the time spent by the analyst/designer in collecting all the necessary information.

\section{General Remarks}

A stand-alone computational simulation procedure has been demonstrated for multidisciplinary analysis and tailoring of an aircraft engine fan blade under simultaneous thermal/structural/vibration/acoustic loading in hot and humid propulsion environments. The information generated for each discipline-specific design with optimization of maximum temperature, maximum temperature gradient, vibration frequency, and acoustic noise, demonstrate the effectiveness of multidisciplinary computational simulation and the various, sometimes competing design requirements. Results for tailored design variables, such as those related to the composite configuration, required for the optimum response obtained from all the involved disciplines, provide a complete set of comprehensive multidisciplinary boundaries for various design parameters. And, the results, such as the decrease in tailored vibration frequency and increase in tailored acoustic noise levels by accounting for environmental effects, exhibit the significance of coupled multidisciplinary simulation of the blade. In an effort to satisfy the competing requirements imposed by individual discipline-specific behavior, many design variations/parameters will need to be considered. Multidisciplinary computational simulation is the approach that will provide a realistic assessment of the various competing design requirements of advanced composite materials/structures. Unlike experimental data generation that may be untimely and costly, computational simulation is able to produce rapid reasonable results for specific designs.

\section{Summary}

A general-purpose computational simulation procedure is presented for coupled multidisciplinary thermal, structural, vibration, and acoustic analysis and tailoring of hot composite structures in propulsion environments. All the disciplines are coupled for nonlinear geometrical, material, loading, and environmental effects. The thermal, mechanical, and acoustic properties of the composite material are nonlinear function of design parameters such as temperature and environments. The procedure is embedded in a stand-alone stateof-the-art computer code, enabled by integrating the three dimensional finite element technique with in-house codes for integrated composite mechanics, thermal/acoustic analysis, and optimization methods. A nonlinear material characterization model is used to simulate the degradation in material properties due to applied temperature, time, and environmental effects. Sample cases exhibiting multidisciplinary tailoring of an aircraft engine fan blade, were presented. Results lead to reduced temperatures and substantially reduced temperature gradients, reduced or increased vibration frequencies depending on the design needs, significantly reduced acoustic noise, and reduced material cost/structure weight for the tailored design of the composite fan blade structure. Collectively, the resuits provide a wealth of information for effective urilization of composite materials/structures. 


\section{References}

1. Chamis, C.C., "Design and Analysis of Fiber Composite Structural Components: Aerospace Structural Materials", NASA SP-227, pp. 217-228, 1970.

2. "A Guide to NASA Lewis Structural Mechanics Codes", NASA Report (under preparation).

3. Hayes, P.E., "Determining Vibration, Radiation Efficiency, and Noise Characteristics of Structural Designs Using Analytical Techniques", Proceedings - Society of Automotive Engineers, p-106, SAE, Warrendale, PA, pp. 236-270, 1982 .

4. Murthy, P.L.N, and Chamis, C.C., "Integrated Composite Analyzer (ICAN) User's and Programmer's Manual, NASA TP 2515, March, 1986.

5. Vanderplaats, G. N., "CONiIN - A Fortran Program For Constrained Function Minimization", NASA TM X-62, 282, August 1973.

6. Chamis, C.C., "Simplified Composite Micro-Mechanics Equations for Hygral, Thermal, and Mechanical Properties", NASA TM-83320, 1987.

7. Chamis, C.C. and Singhal, S.N., "Coupled Multidisciplinary Simulation of Composite Engine Structures in Propulsion Environment", to be presented at the 1992 ASME Turbo Expo, Cologne, Germany.

8. Saravanos, D.A. and Chamis, C.C., "Mechanics of Damping for Fiber Composite Laminates Including Hygrothermal Effects", AIAA Journal Vol. 28, 非10, pp $1813-1819,1990$.

9. Saravanos, D.A. and Chamis, C.C., "Multiobjective Shape and Material Optimization of Composite Structures Including Damping", AIAA Journal, Vol. 30, \#3, pp 805-813, March 1992. 


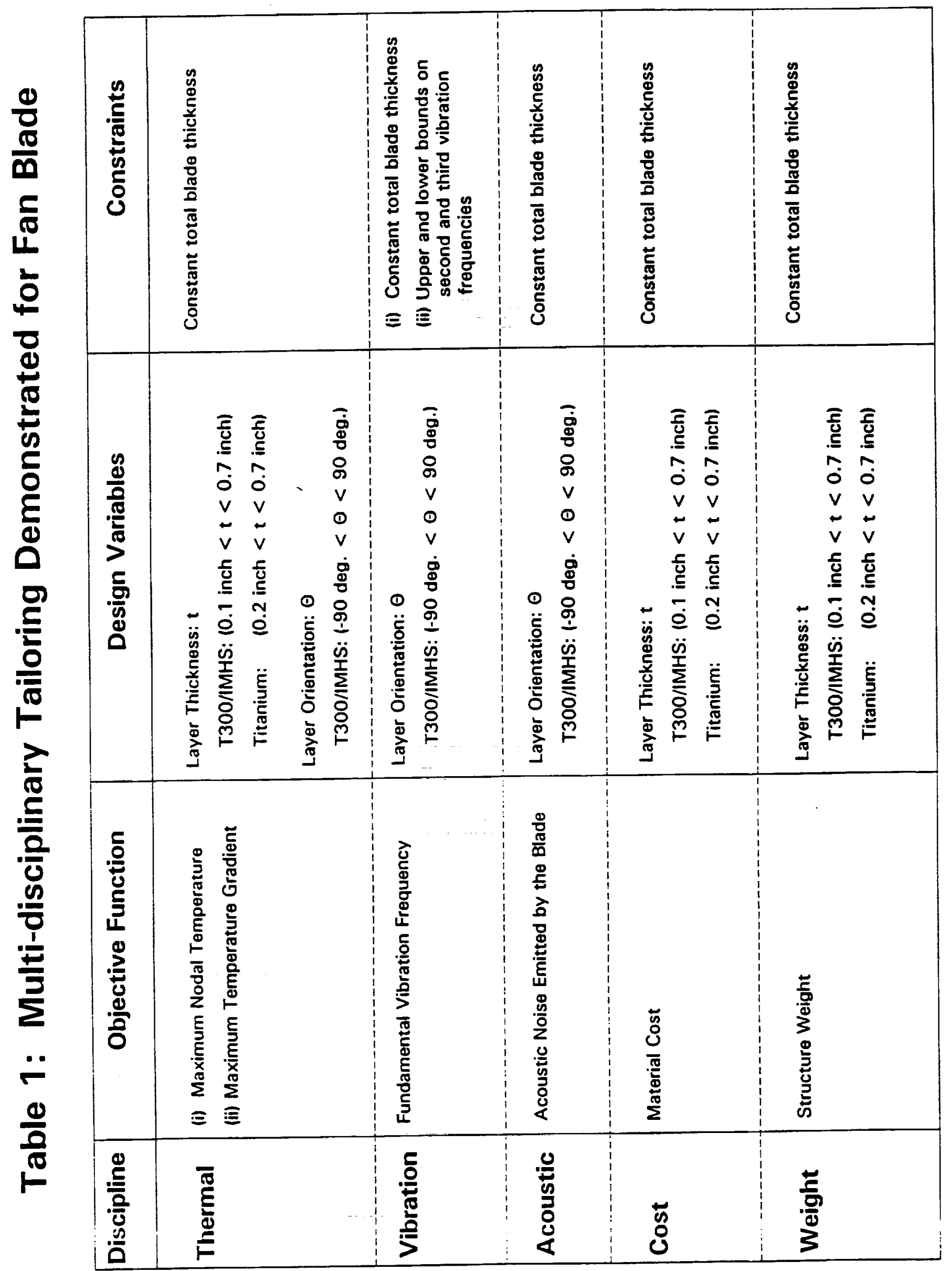




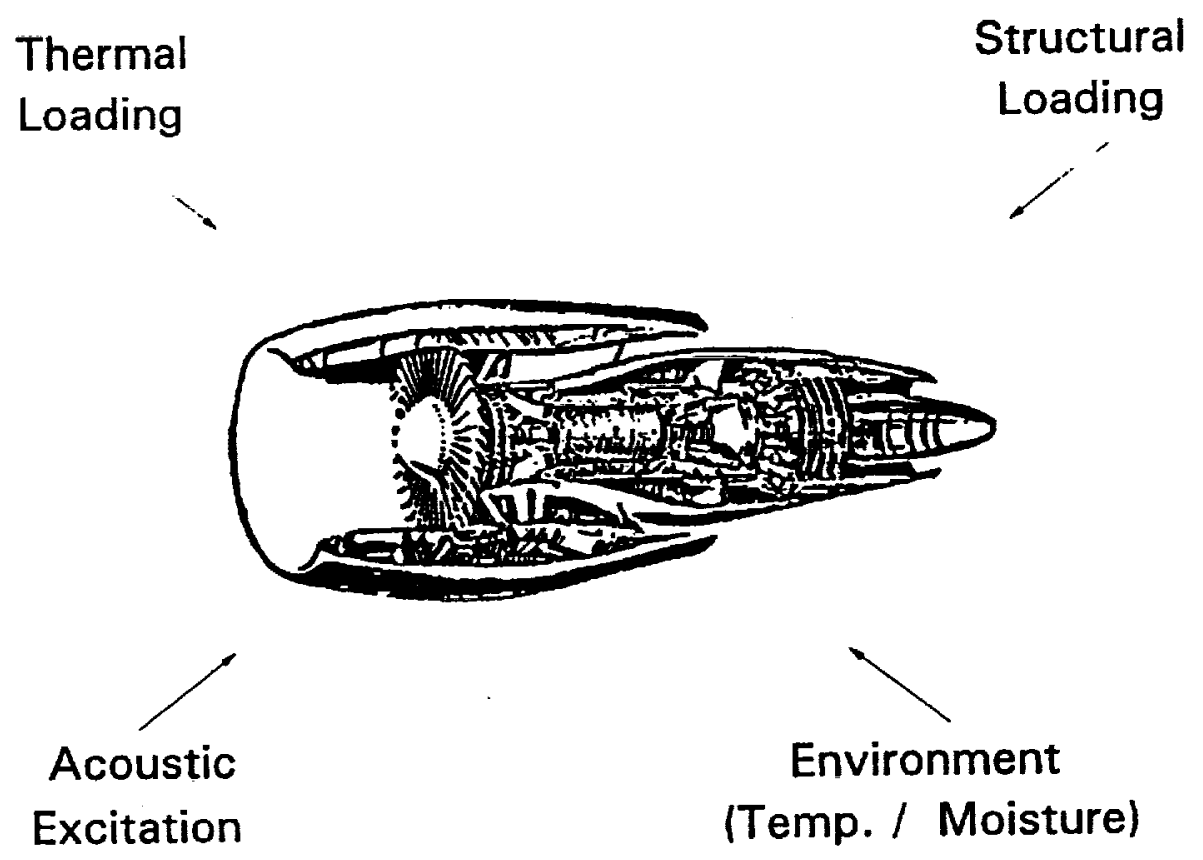

Fig. 1: Engine Components Under Multidisciplinary Loadings

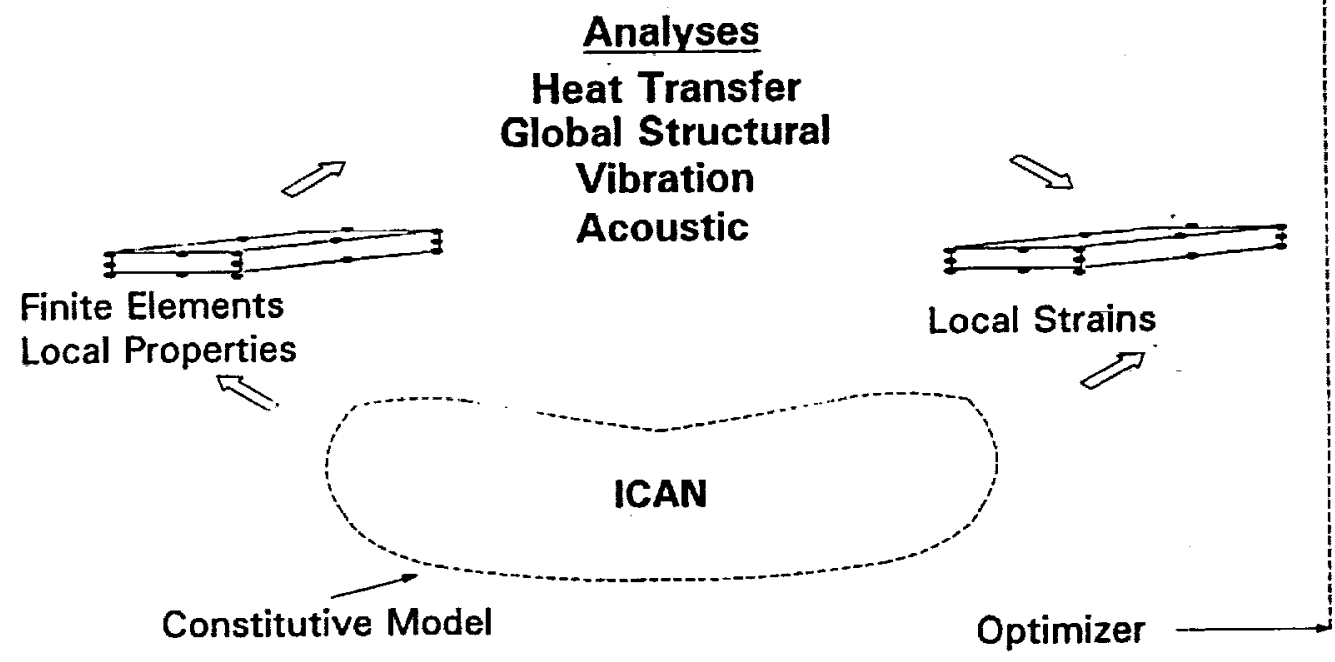

Fig. 2: Multidisciplinary Analysis/Tailoring Coupled with Integrated Composite Analyzer 


\section{Component}

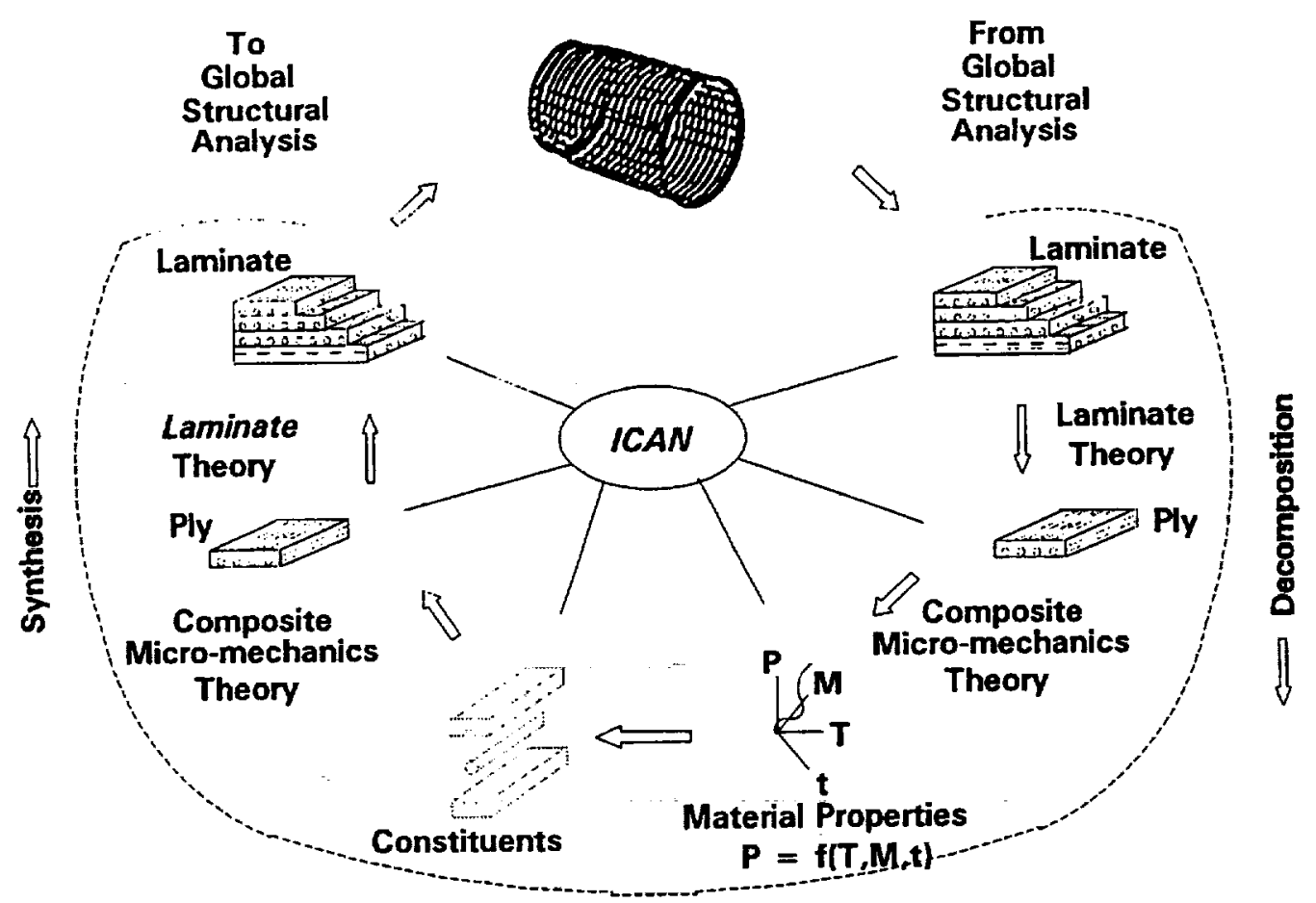

Fig. 3: Integrated Composite Analyzer (ICAN)

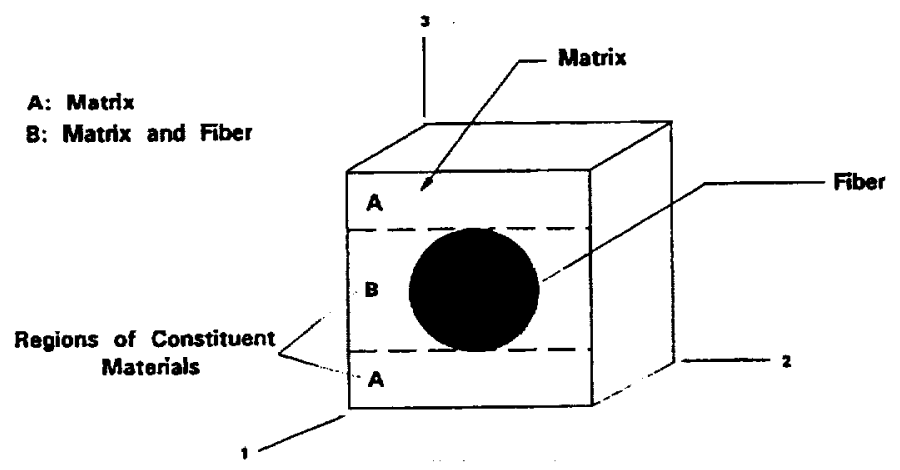

$$
\begin{aligned}
& \frac{P_{M}}{P_{M 0}}=\left[\frac{T_{G W}-T}{T_{G D}-T_{0}}\right]^{1 / 2} \\
& T_{G W}=10.005 M^{2}-0.1 M+1 / T_{G D}
\end{aligned}
$$$$
\mathbf{P}_{M}=\text { Matrix Property at Current Temp., } T
$$$$
P_{\text {Mo }}=\text { Matrix Property at Reference Temp., } T_{0}
$$$$
T_{\text {GW }}=\text { Wet Glass Transition Temp. }
$$$$
T_{G D}=\text { Dry Glass Transition Temp. }
$$

M = Moisture

Fig. 4: Regions of Constituent Materials and Nonlinear Material Characterization Model 


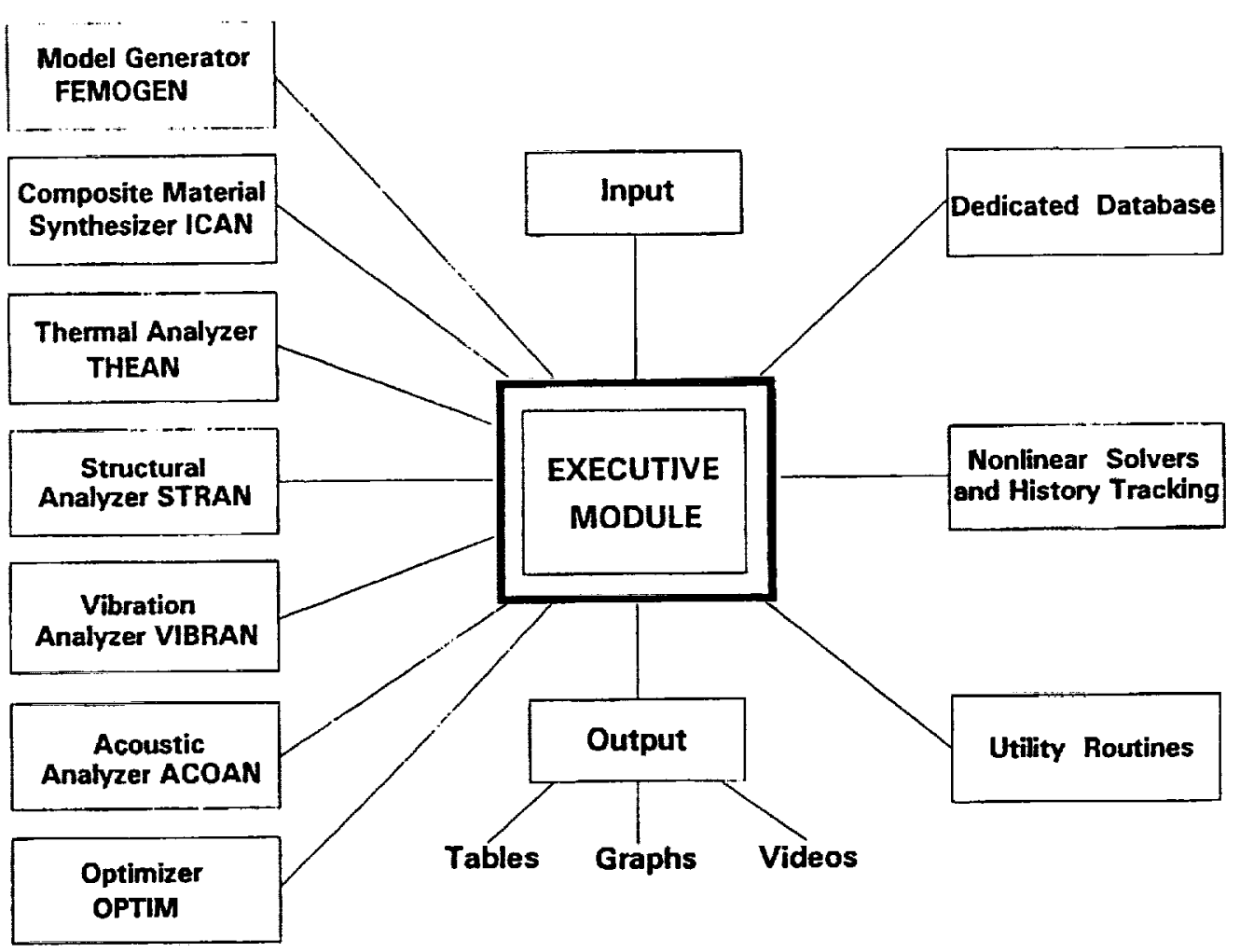

Fig. 5: Multidisciplinary Modular Structure

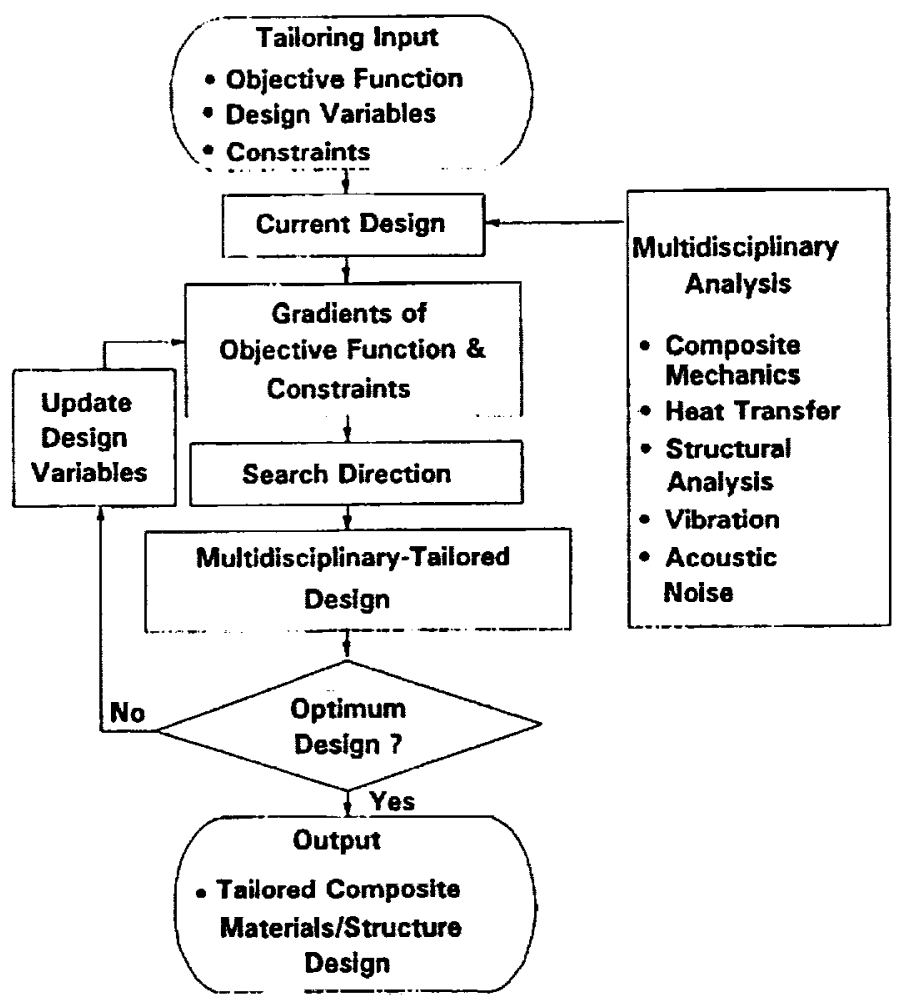

Fig. 6: Multidisciplinary Tailoring Procedure 


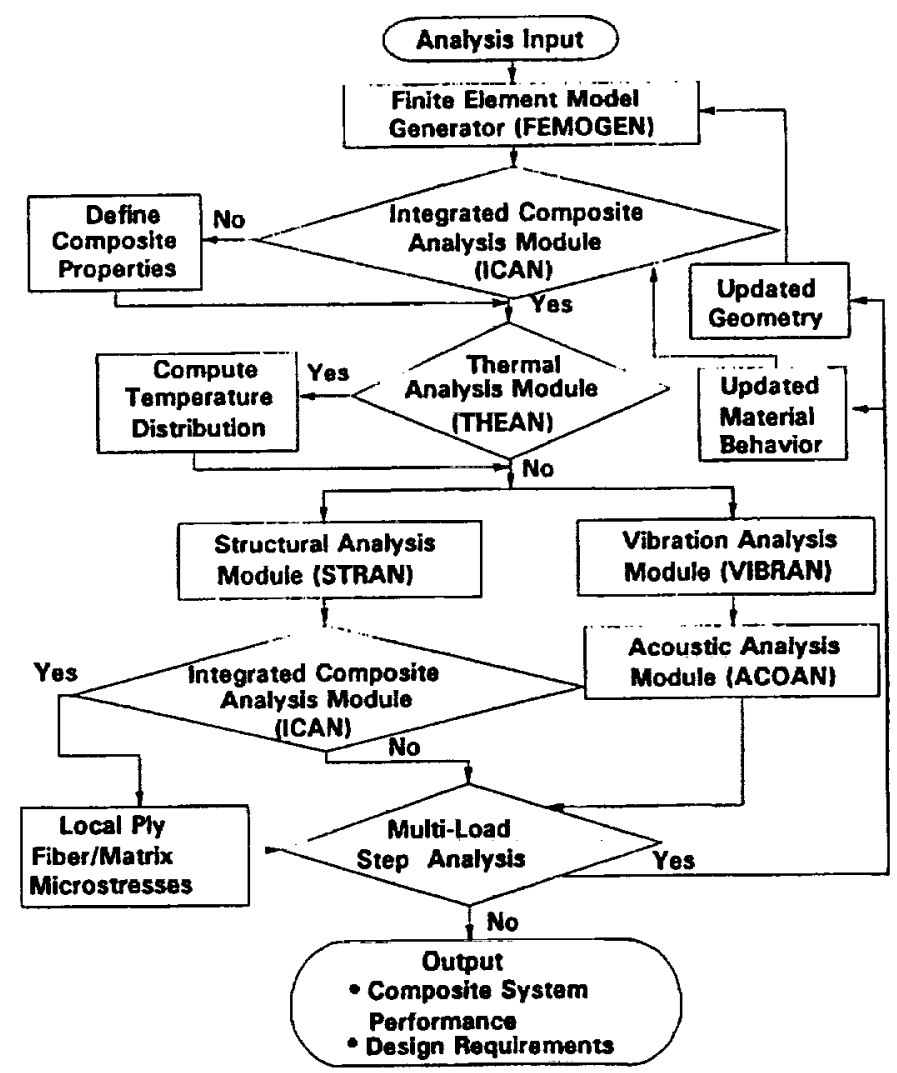

Fig. 7: Multidisciplinary Analysis Procedure

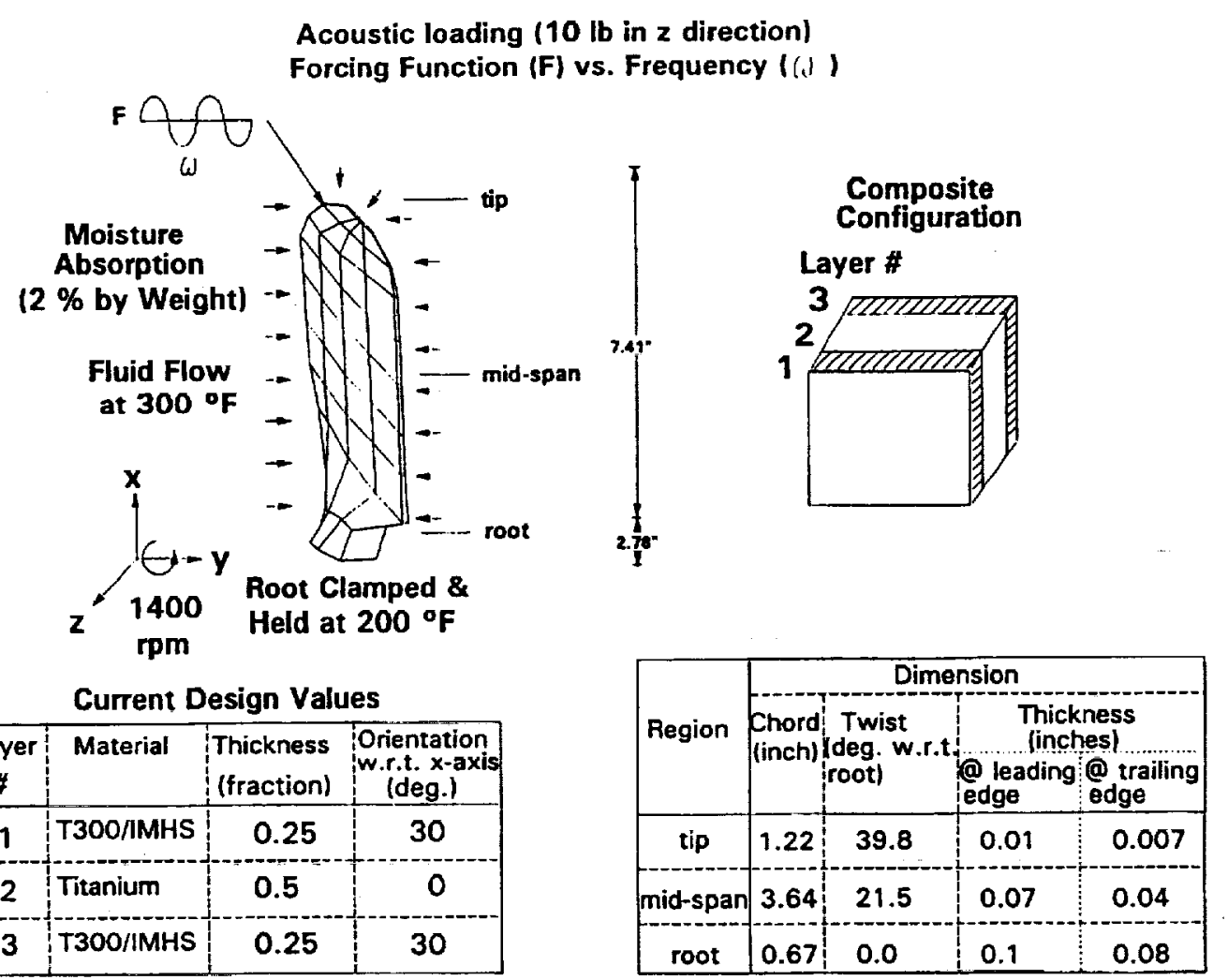

Fig. 8: Fan Blade: Current Design under Multidisciplinary Loading 
$\begin{array}{ll}\text { Objective: } & \text { Minimize Maximum Temperature Difference } \\ \text { Design Variables: } & \text { Layer Thicknesses } 10.1<\text { Layer Thickness }<0.7) \text { for T300/MMS }\end{array}$

$(0.2<$ Layer Thickness $<0.7)$ for Titanium T300/IMHS Layer Orientations (-90 deg. < Layer Orientation < 90 deg.)

Constraint: $\quad$ Constant Total Thickness

Fluid Flow

@ $300^{\circ} \mathrm{F}$<smiles>[X]C([Y])[X]</smiles>

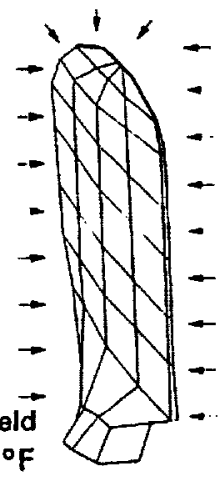

Composite Configuration Before Tailoring

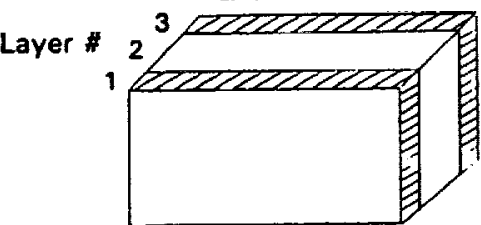

(Max. temp. difference $\left.=83^{\circ} \mathrm{F}\right)$

$17.2 \%$ Reduction in Max. temp. difference

@ $200^{\circ} \mathrm{F}$

in Max. temp.

After Tailoring

Design Before After Tailoring

\begin{tabular}{|c|c|c|c|c|c|}
\hline \multirow[t]{2}{*}{ Layer } & \multirow[t]{2}{*}{ Material } & \multicolumn{2}{|c|}{$\begin{array}{l}\text { Thickness } \\
\text { (fraction) }\end{array}$} & \multicolumn{2}{|c|}{$\begin{array}{c}\text { Orientation } \\
\text { w.r.t. } x \text {-axis } \\
\text { (deg.) }\end{array}$} \\
\hline & & Betora & After & Beforo & After \\
\hline 1 & T300/MHS & 0.25 & 0.21 & 30 & -12.8 \\
\hline 2 & Titanium & 0.5 & 0.20 & 0 & 0 \\
\hline 3 & T300MMHS & 0.25 & 0.59 & 30 & 5.2 \\
\hline
\end{tabular}

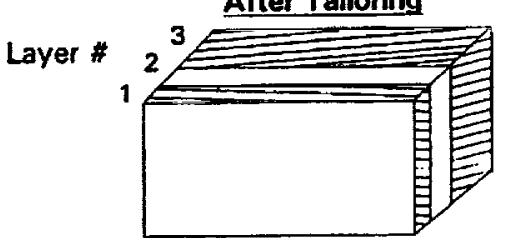

(Max. temp. difference $=68.7^{\circ} \mathrm{F}$ )

Fig. 9: Thermal Tailoring of Composite Fan Blade: Design Before and After Tailoring
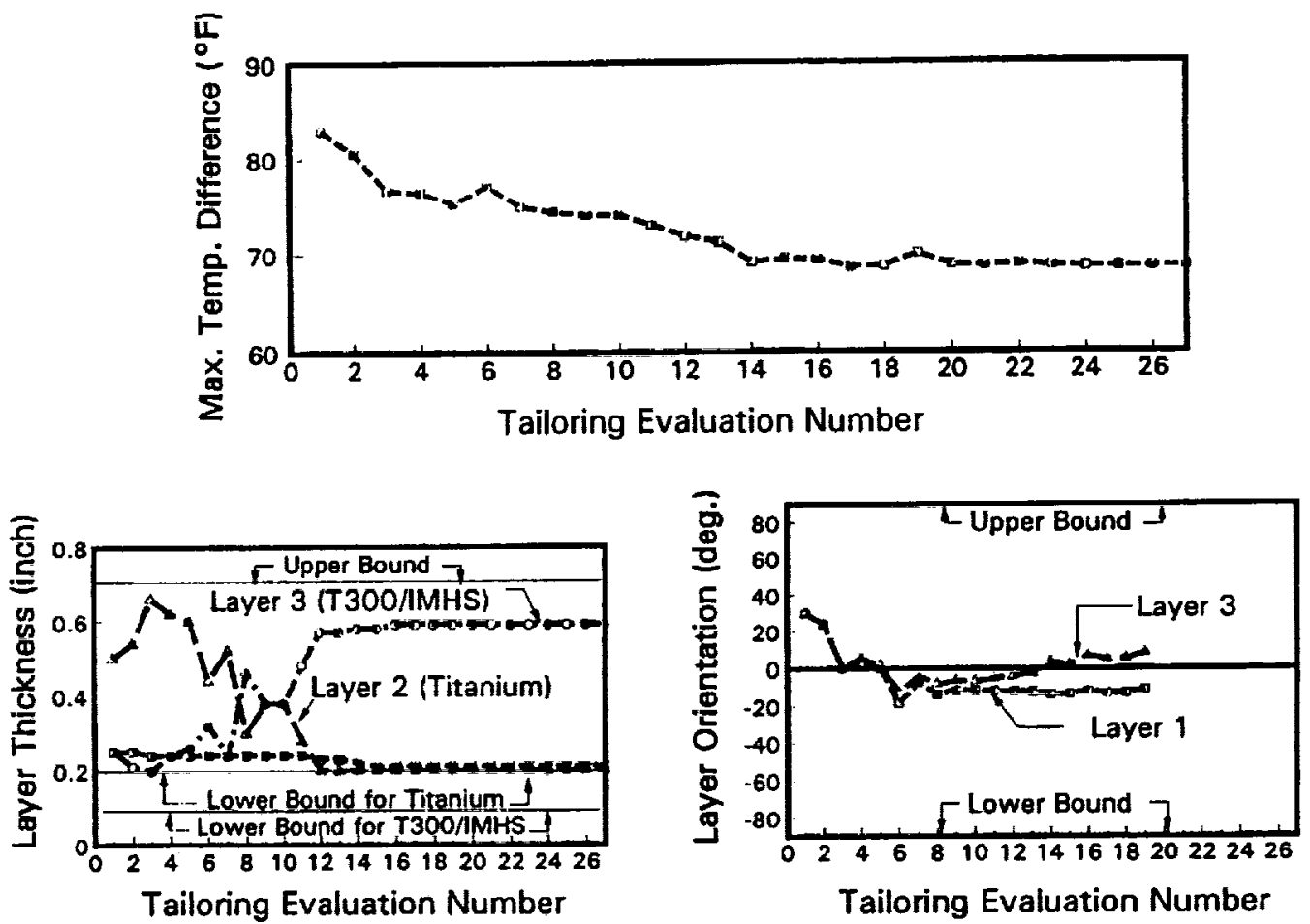

Fig. 10: Thermal Tailoring of Composite Fan Blade: Tailoring Path 
Objective: Maximize Fundamental Vibration Frequency

Design Variables: T300/IMHS Layer Orientations (-90 deg. < Layer Orientation < 90 deg.)

Constraint: Constant Total Thickness $20 \mathrm{cps}<\mathrm{f}_{2}, \mathrm{f}_{3}<500 \mathrm{cps}$

$f_{2}$ : Second Vibration Frequency

$f_{3}$ : Third Vibration Frequency

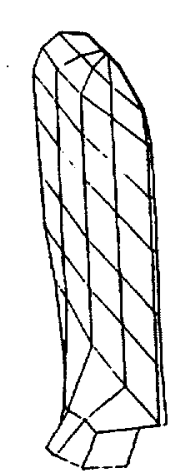

Composite Configuration<smiles>[Z]C([Y])[X]</smiles>

\section{Before Tailoring}

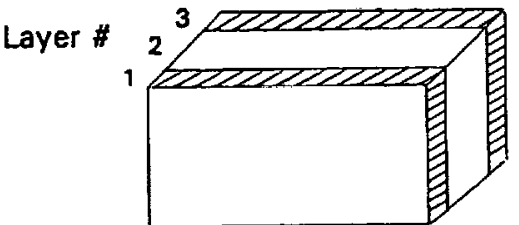

(fundamental vibration frequency $=79.1 \mathrm{cps}$ )

$64.2 \%$ Increase in Frequency

Design Before \& After Tailoring

\begin{tabular}{|c|c|c|c|c|}
\hline \multirow[t]{2}{*}{ Layer } & \multirow[t]{2}{*}{ Material } & \multicolumn{2}{|c|}{$\begin{array}{c}\text { Orientation } \\
\text { w.r.t. x-axis } \\
\text { (deg.) }\end{array}$} & \multirow[t]{2}{*}{$\begin{array}{l}\text { Thickness } \\
\text { (fraction) }\end{array}$} \\
\hline & & Before & After & \\
\hline 1 & T300/MHS & 30 & -4.7 & 0.25 \\
\hline 2 & Titanium & 0 & 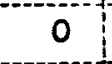 & 0.5 \\
\hline 3 & T300лMHS & 30 & -3.5 & 0.25 \\
\hline
\end{tabular}

\section{After Tailoring}

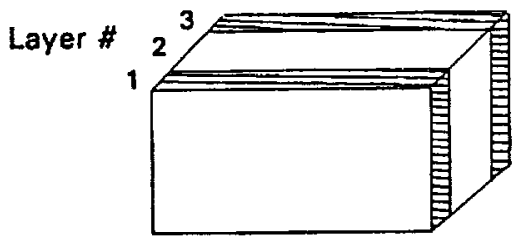

(fundamental vibration frequency $=129.9 \mathrm{cps}$ )

Fig. 11: Vibration of Composite Fan Blade: Design Before and After Tailoring
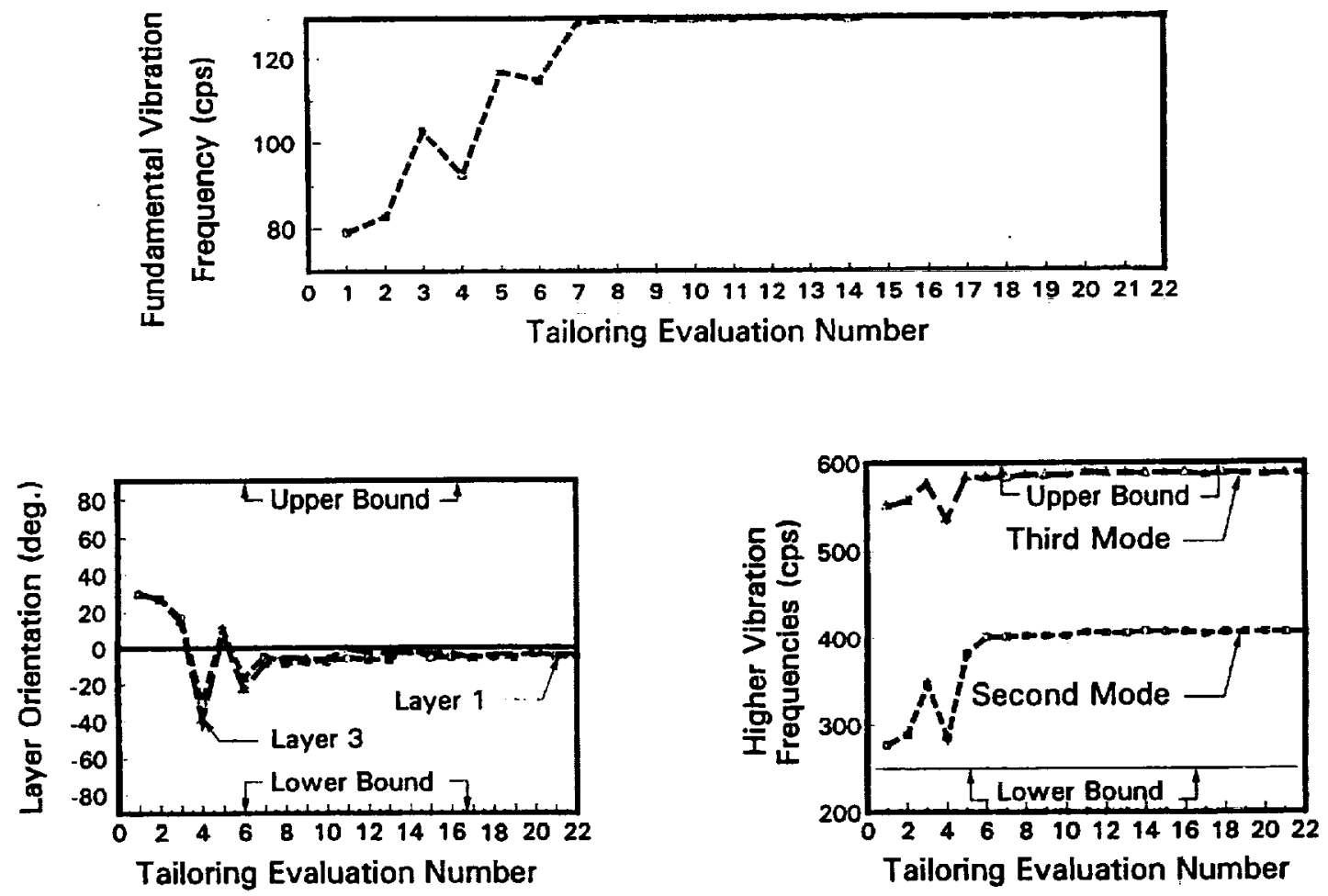

Fig. 12: Vibration of Composite Fan Blade: Tailoring Path 
Objective: Minimize Acoustic Noise

Design Variables: T300/IMHS Layer Orientations (-90 deg. < Layer Orientation < 90 deg.)

Constraint: Constant Total Thickness

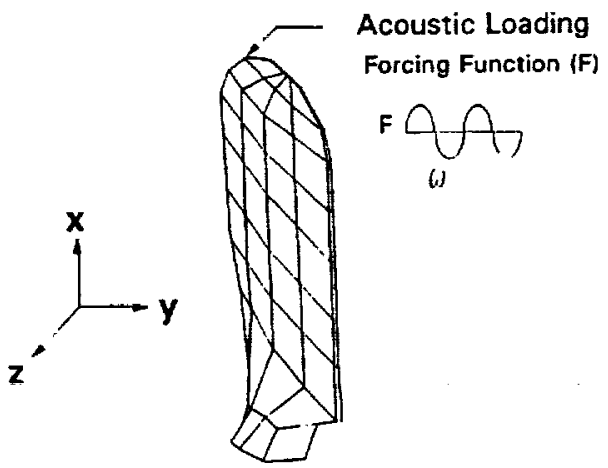

$\omega:$ Frequency of Forcing Function

Design Before \& After Tailoring

\begin{tabular}{|c|c|c|c|c|}
\hline \multirow[t]{2}{*}{$\begin{array}{c}\text { Layer } \\
\#\end{array}$} & \multirow[t]{2}{*}{ Material } & \multicolumn{2}{|c|}{$\begin{array}{l}\text { Orientation } \\
\text { w.r.t. } x \text {-axis } \\
\text { (deg.) }\end{array}$} & \multirow[t]{2}{*}{$\begin{array}{l}\text { Thickness } \\
\text { (fraction) }\end{array}$} \\
\hline & & Before & After & \\
\hline 1 & T300/MHS & 30 & -3.7 & 0.25 \\
\hline 2 & Titanium & 0 & 0 & 0.5 \\
\hline 3 & T300/NMHS & 30 & -1.7 & 0.25 \\
\hline
\end{tabular}

Composite Configuration

Before Tailoring

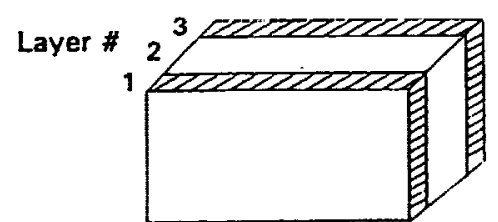

(Acoustic Noise $=0.004154$ watts or $95.5 \mathrm{db}$ )

$85.3 \%$ Reduction in Noise Power

$8.7 \%$ Reduction in Noise (db)

After Tailoring

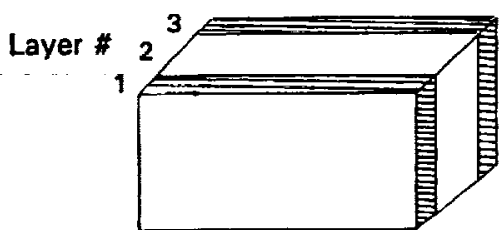

(Acoustic Noise $=0.0006091$ watts or $87.2 \mathrm{db}$ )

Fig. 13 Acoustic Tailoring of Composite Fan Blade: Design before and AfterTailoring

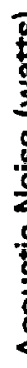


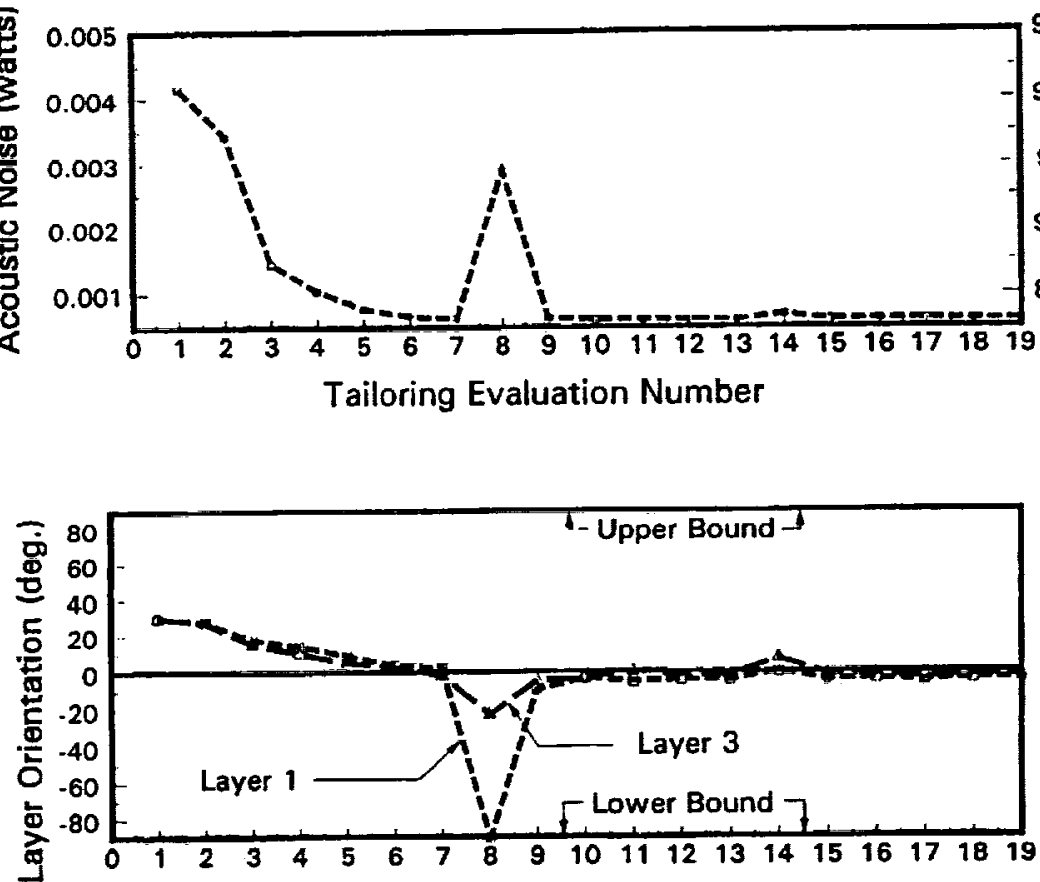

Tailoring Evaluation Number

Fig. 14: Acoustic Tailoring of Composite Fan Blade: Tailoring Path 
Objective: Minimize Material Cost

Design Variables: Layer Thicknesses $(0.1<$ Layer Thickness $<0.7)$ for T300/IMHS

$10.2<$ Layer Thickness $<0.7\}$ for Titanium

Constraint: Constant Total Thickness
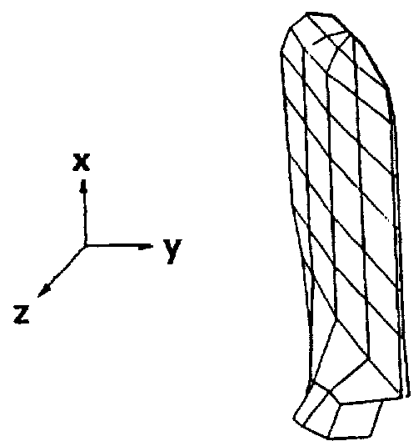

Composite Configuration

Before Tailoring

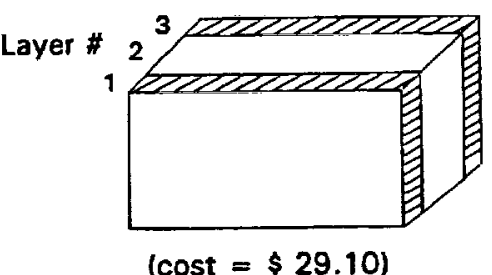

Design Before \& After Tailoring

\begin{tabular}{|c|c|c|c|c|c|}
\hline \multirow[t]{2}{*}{$\begin{array}{c}\text { Layer } \\
\#\end{array}$} & \multirow[t]{2}{*}{ Material } & \multirow{2}{*}{$\begin{array}{l}\text { Cost } \\
(\$ / \mathrm{b})\end{array}$} & \multicolumn{2}{|c|}{$\begin{array}{l}\text { Thickness } \\
\text { (fraction) }\end{array}$} & \multirow{2}{*}{$\begin{array}{c}\text { Orientation } \\
\text { w.r.t. x-axis } \\
\text { (deg.) }\end{array}$} \\
\hline & & & Before & After & \\
\hline 1 & T300/IMHS & 20 & 0.25 & 0.15 & 30 \\
\hline 2 & Titanium & 4 & 0.5 & 0.7 & 0 \\
\hline 3 & T300AMHS & 20 & 0.25 & 0.15 & 30 \\
\hline
\end{tabular}

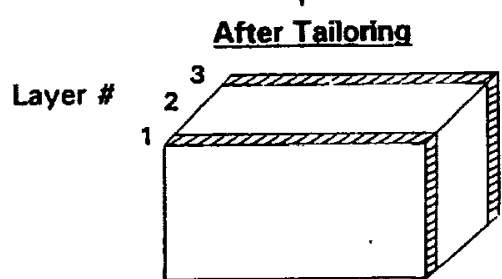

$($ cost $=\$ 21.30)$

Fig. 15: Cost Tailoring of Composite Fan Blade: Design Before and After Tailoring

Objective: Minimize Structure Weight

Design Variables: Layer Thicknesses $(0.1<$ Layer Thickness $<0.7)$ for T300/IMHS $(0.2<$ Layer Thickness $<0.7)$ for Titanium

Constraint: $\quad$ Constant Total Thickness

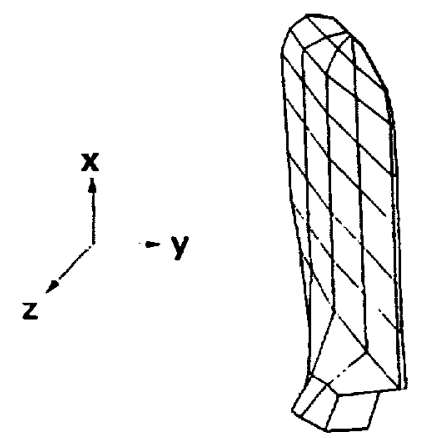

Composite Configuration

Betore Tailoring

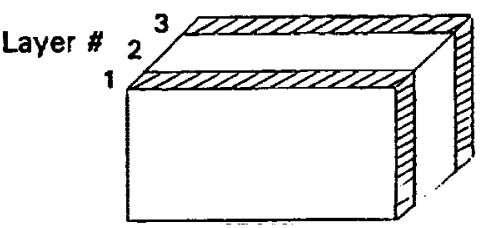

(weight $=0.44 \mathrm{lb}$ )

$29.5 \%$ Reduction in Weight

Design Before \& After Tailoring

\begin{tabular}{|c|c|c|c|c|c|}
\hline \multirow[t]{2}{*}{$\begin{array}{c}\text { Layer } \\
\#\end{array}$} & \multirow[t]{2}{*}{ Material } & \multirow{2}{*}{$\begin{array}{l}\text { Density } \\
\left(\mathrm{b} / \mathrm{in}^{3}\right)\end{array}$} & \multicolumn{2}{|c|}{$\begin{array}{l}\text { Thickness } \\
\text { (fraction) }\end{array}$} & \multirow{2}{*}{$\begin{array}{l}\text { Orientation } \\
\text { w.r.t. x-axis } \\
\text { (deg.) }\end{array}$} \\
\hline & & & Before & After & \\
\hline 1 & T300/IMHS & 0.056 & 0.25 & 0.25 & 30 \\
\hline 2 & Titanium & 0.161 & 0.5 & 0.2 & 0 \\
\hline 3 & T300/MHS & 0.056 & 0.25 & 0.55 & 30 \\
\hline
\end{tabular}

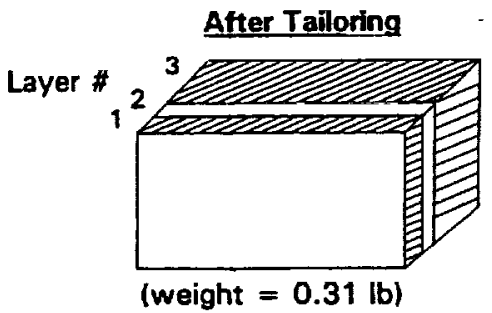

Fig. 16 Weight of Composite Fan Blade: Design Before and After Tailoring 


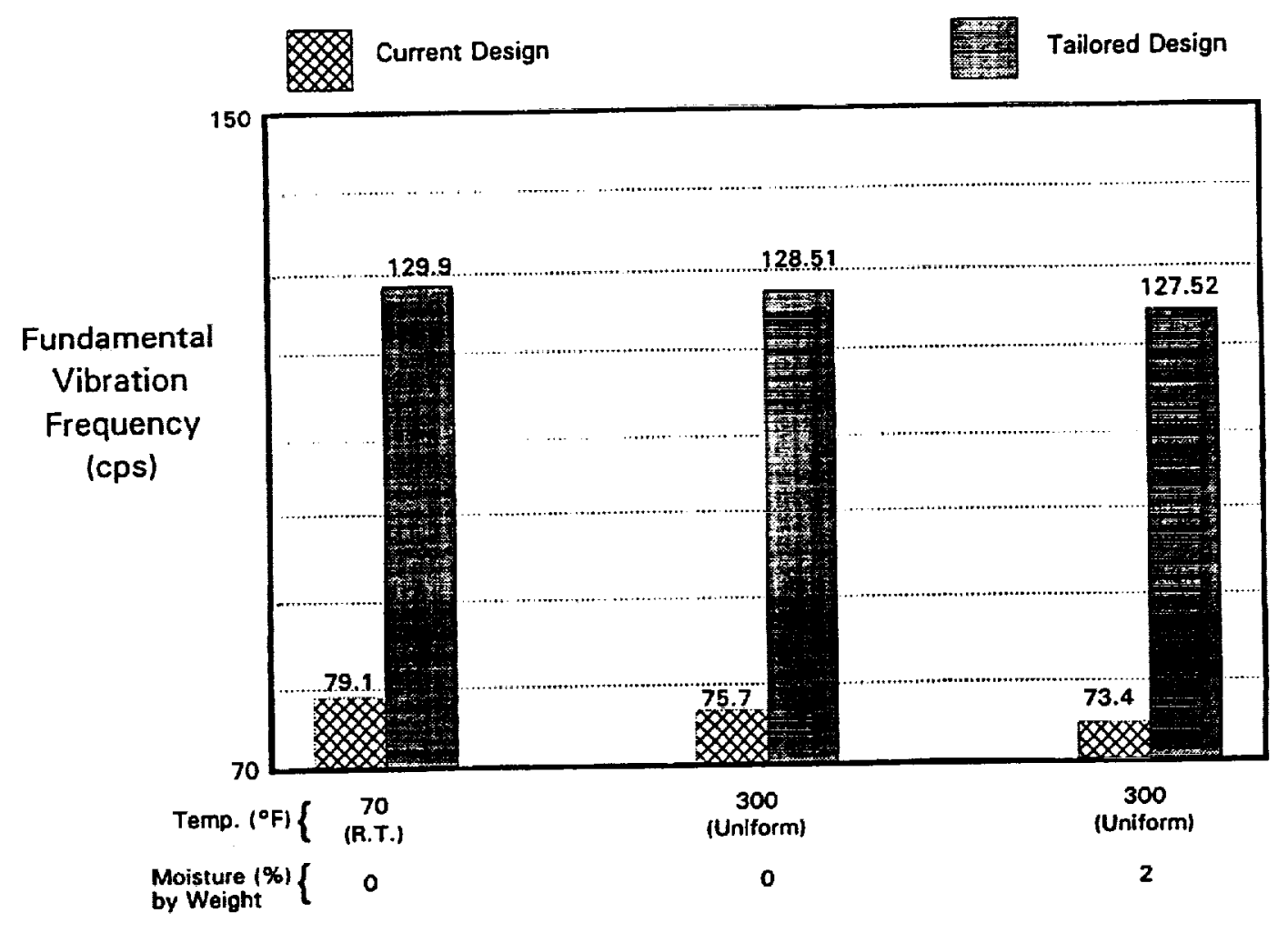

Fig. 17: Vibration Tailoring of Composite Fan Blade-Effect of Environments

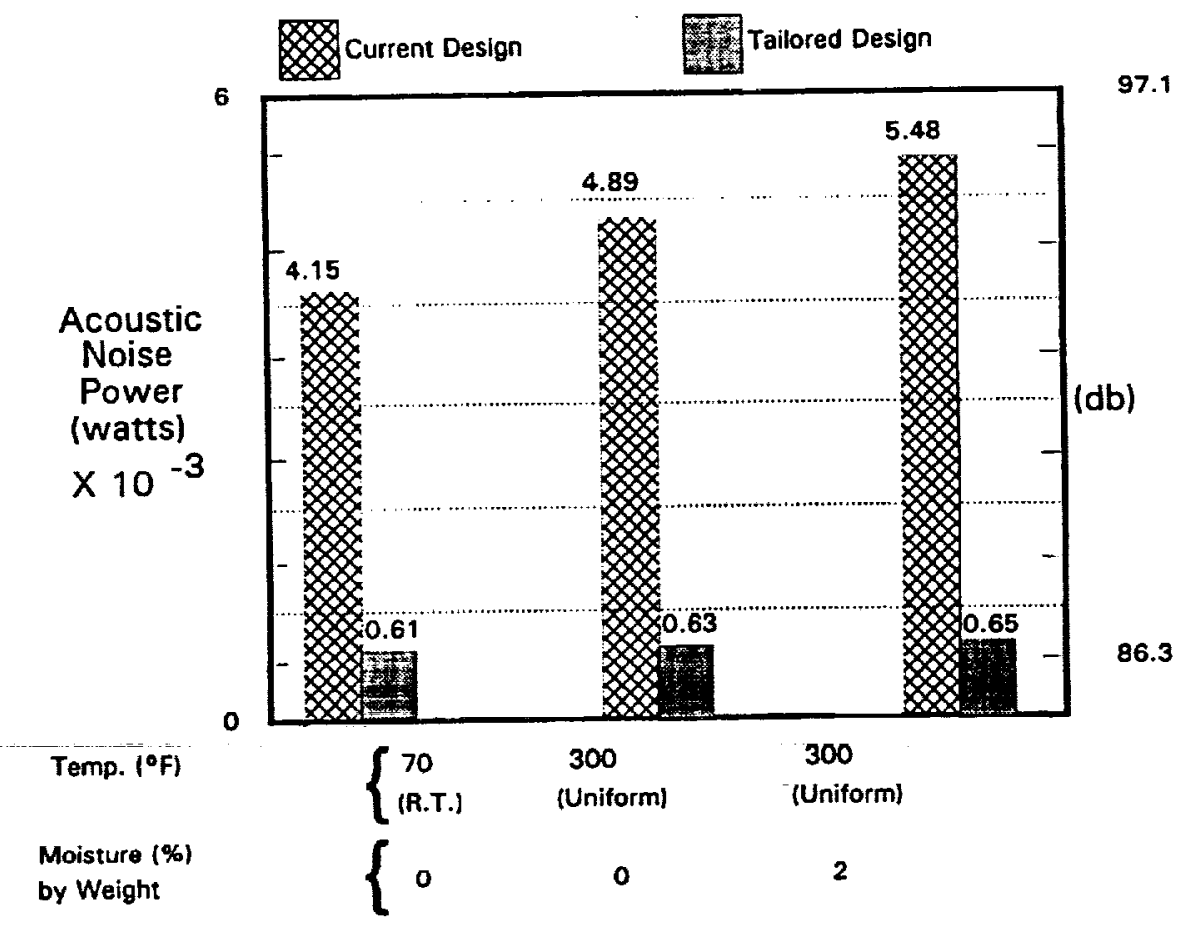

Fig. 18: Acoustic Tailoring of Composite Fan Blade - Effect of Environments 
Public reporting burden for this collection of information is estimated to average 1 hour per response, including the time for reviewing instructions, searching existing data sources, Public reponting burdening the data needed, and completing and reviewing the collection of information. Send comments regarding this burden estimate or any other aspect of this gathering and maintaining the data needed, and for reducing this burden, to Washington Headquarters Senves, Direciorate for information Operations and Peports, 1215 Jefterson Davis Highway, Suite 1204, Arlington, VA 22202-4302, and to the Office of Managenent and Budges, Paperwork Reduction Project (0704-0188). Washington, DC 20503.

\begin{tabular}{|l|c|c|}
\hline 1. AGENCY USE ONLY (Leave blank) & $\begin{array}{r}\text { 2. REPORT DATE } \\
\text { February } 1993\end{array}$ & $\begin{array}{r}\text { 3. REPORT TYPE AND DATES COVERED } \\
\text { Technical Memorandum }\end{array}$
\end{tabular}

4. TTLE AND SUBTITLE

5. FUNDING NUMBERS

Multidisciplinary Tailoring of Hot Composite Structures

6. AUTHOR(S)

Surendra N. Singhal and Christos C. Chamis

\section{PERFORMING ORGANIATION NAME(S) AND ADDRESS(ES)}

Sverdrup Technology, Inc.

Lewis Research Center Group

2001 Aerospace Parkway

Brook Park, Ohio 44142

9. SPONSORING/MONITORING AGENCY NAMES(S) AND ADDRESS(ES)

National Aeronautics and Space Administration

Lewis Research Center

Cleveland, Ohio 44135-3191
8. PERFORMING ORGANIZATION REPORT NUMBER

E-7589

10. SPONSORINGMONITORING AGENCY REPORT NUMBER

NASA TM-106027

11. SUPPLEMENTARY NOTES

Prepared for the 33rd Structures, Structural Dynamics and Materials Conference cosponsored by AIAA, ASME, ASCE, AHS, and ASC, Dallas, Texas, April 13-15, 1993. Surendra N. Singhal, Sverdrup Technology, Inc., Lewis Research Center Group, 2001 Aerospace Parkway,

Brook Park, Ohio 44142; and Christos C. Chamis, NASA Lewis Research Center, Cleveland, Ohio. Responsible person, Christos C. Chamis, (216) 433-3252.

12a. DISTRIBUTION/AVAILABILITY STATEMENT

Unclassified - Unlimited

Subject Category 39

\section{ABSTRACT (Maximum 200 words)}

A computational simulation procedure is described for multidisciplinary analysis and tailoring of layered multi-material hot composite engine structural components subjected to simultaneous multiple discipline-specific thermal, structural, vibration, and acoustic loads. The effect of aggressive environments is also simulated. The simulation is based on a three-dimensional finite element analysis technique in conjunction with structural mechanics codes, thermal/acoustic analysis methods, and tailoring procedures. The integrated multidisciplinary simulation procedure is general-purpose including the coupled effects of nonlinearities in structure geometry, material, loading, and environmental complexities. The composite material behavior is assessed at all composite scales, i.e., laminate/ply/constituents (fiber/matrix), via a nonlinear material characterization hygro-thermo-mechanical model. Sample tailoring cases exhibiting nonlinear material/loading/environmental behavior of aircraft engine fan blades, are presented. The various multidisciplinary loads lead to different tailored designs, even those competing with each other, as in the case of minimum material cost versus minimum structure weight and in the case of minimum vibration frequency versus minimum acoustic noise.

14. SUBJECT TERMS

Acoustic excitation; Acoustic noise; Composites; Cost; Environmental effect; Heat transfer; Hygro-thermomechanics; Multidisciplinary analysis; Multidisciplinary tailoring; Nonlinear geometry; Nonlincar material; Nonlinear loading; Nonlinear environmental effects; Optimization; Polymer matrix composites; Simulation; Structural analysis; Tailoring; Thermal response; Vibration; Weight

\begin{tabular}{l|l} 
17. SECURITY CLASSIFICATION & 18. SECURITY CLASSIFICATION
\end{tabular} OF REPORT

\section{SECURITY CLASSIFICATION} OF ABSTRACT

Unclassified 